\title{
Distance of Movements of Voles after Removal in Clethrionomys rufocanus bedfordiae (Rodentia: Cricetidae)
}

\author{
Keisuke NaKaTA and Kazuhiro SATOH ${ }^{1}$ \\ Hokkaido Forestry Research Institute, Bibai, Hokkaido 079-01, Japan \\ 1 Ohmu Forestry Office, Forestry Division, Hokkaido Government, \\ Ohmu, Hokkaido 098-17, Japan
}

(Received 30 June, 1993; Accepted 21 October, 1993)

\begin{abstract}
Movements of individual voles were monitored in a homogenous habitat in relation to reduction of high-density populations of the gray red-backed vole, Clethrionomys rufocanus bedfordiae. By two weeks after more than $80 \%$ of residents were removed in late autumn, over $90 \%$ of the voles initially located within $30 \mathrm{~m}$ of the edge of removal grid were making single-direction movements toward (or to) the removal grid. Fifty percent or more of the voles located at greater distances from the removal site did not make similar movements. Mean distances of movements toward (or to) the removal grid ranged from $30.6 \mathrm{~m}$ to $52.4 \mathrm{~m}$ in both sexes; sex-related difference was insignificant. After more than two weeks, few voles moved into the removal grid from the adjacent grid, though the vole numbers were still lower in the former.
\end{abstract}

Key words: movement, dispersal, reinvasion, depopulation, Clethrionomys rufocanus

\section{INTRODUCTION}

Movements of animals into removal areas have been studied to elucidate not only the role of dispersal on population regulation but also the process of reinvasion after rodenticide applications (e.g., Gaines and Johnson, 1987; Stenseth, 1977). Reinvasion of pests into the treated area makes the control effect null, so much effort has been made to develop counterplans. Two major points may be summarized from these studies. First, when depopulation is conducted in a homogenous habitat, singledirection movements are induced from high-density areas to low-density areas (e.g., VAN VLECK, 1968; Higuchi et al., 1968). Second, the smaller the treated area and/or the higher the adjacent population density, the faster the reinvasion occurs (e.g., Kozakiewicz, 1976; Hrguchi, 1977). For instance, in smaller plantations of less than $4 \mathrm{ha}$, the number of voles was restored to $30-50 \%$ of the original level within two weeks after depopulation (BLAIR, 1940; Higuchi et al., 1968; NAKATA et al., 1979). In reinvasion, however, the source of animals moving into a depopulated area and their distance of movements is still not fully clarified.

In silvicultural operations, reforestation sites have recently diminished in size, and plantations smaller than 1 ha are increasing in Hokkaido. Since perimeter area is proportionately higher in smaller plantations, voles' reinvasion to these areas often becomes major deterrent to reforestation. This is an urgent control problem. To 
what extent is a perimeter buffer strip needed with rodenticide baiting to prevent rapid reinvasions?

This study used removal trapping of high-density populations of the gray redbacked vole, Clethrionomys rufocanus bedfordiae, and monitored movements of voles to clarify (1) the source of individuals moving into the removal grid, and (2) the distance of movements from these sources.

\section{STUDY AREA AND METHODS}

The study area was a wind-shelterbelt that crosses paddy fields at Koshunai $\left(43^{\circ} 18^{\prime}\right.$ $\left.\mathrm{N}, 141^{\circ} 49^{\prime} \mathrm{E}\right)$, Bibai, Hokkaido, Japan. This shelterbelt is a wooded habitat consisting of larch (Larix leptolepis) and ash (Fraxinus mandshurica var. japonica), with a homogenous undergrowth of dense sasa bamboo (Sasa senanensis) of $1.1 \mathrm{~m}$ in height and about 60 culms to a square meter. The area was $550 \times 60 \mathrm{~m}$, bordered by waterways for irrigation ( $5 \mathrm{~m}$ width $\times 1.5 \mathrm{~m}$ depth) and/or pavements $(12 \mathrm{~m}$ width with drainage channels), and providing a considerable degree of ecological isolation. At one end of the shelterbelt, a removal trapping grid (100-m length) and control grid (110-m or 120-m length) were placed. All trap points were spaced $10 \mathrm{~m}$ apart in an arrangement of $5 \times 22$ in 1989, and of $6 \times 21$ in 1991. One Sherman live trap was placed at every point. Live trapping (capture-mark-release) was done for three consecutive days every survey period. The trapping started on 24 October 1989 and on 23 October 1991. In the removal grid, however, all the voles captured on the first and the second day in 1989 and on all three trapping days in 1991 were removed. After the original removal, two monitored trappings were done until late November: 12 days and 26 days later in 1989, and 13 days and 36 days later in 1991. Hereinafter we refer to a period from the removal trapping to the first monitored trapping as period I, and from the first to the second monitored trapping as period II.

In addition to $C$. rufocanus bedfordiae, the following five individuals of three rodent species were removed from the area: Apodemus argenteus, Rattus norvegicus, and Mus molossinus. Besides the above, 77 Sorex unguiculatus, $30 \mathrm{~S}$. caecutiens saevus individuals, and 1 individual each of Mustela sibirica itatsi and $M$. nivalis were also removed during the two survey years.

In this paper, population density estimates during survey periods were obtained by direct enumeration of voles on the grids. The geometric center of capture points, weighted with capture number, was obtained for each vole every survey period.

\section{RESULTS}

Population density and composition of $C$. rufocanus

Initial population densities on survey grids were over 80 individuals/ha in late October in 1989 and 1991 (Table 1). Such high autumnal densities were thought to be a usual phenomenon in this kind of ecologically isolated shelterbelt (cf., GaInEs and McClenagham, 1980). Abe (1976) also reported similarly high population densities of this species in a wind shelterbelt at Ishikari, Hokkaido.

A summary of demographic attributes of the present population was as follows: lighter individuals less than $25 \mathrm{~g}$, usually subadults (AвE, 1968; Kuwahata, 1976), made up $59-65 \%$ of populations at the initial periods in late autumn. They were 
Table 1. The number of trapped voles during the survey periods

\begin{tabular}{llcccc}
\hline Year & Grid & \multirow{2}{*}{$\begin{array}{c}\text { Size } \\
\text { of Grid } \\
\text { (ha) }\end{array}$} & Initial & Period & II \\
\cline { 5 - 6 } 1989 & Removal & 0.60 & 56 & $32^{\mathrm{a}}$ & $27^{\mathrm{a}}$ \\
& Control & 0.72 & $60^{\mathrm{a}}$ & $54^{\mathrm{a}}$ & $38^{\mathrm{a}}$ \\
& Removal & 0.60 & 104 & 27 & 20 \\
& Control & 0.66 & 81 & 46 & 28 \\
\hline
\end{tabular}

a This value was deduced from the number of voles trapped on the first day, because weasels killed and removed some trapped voles on the second and/or third day.
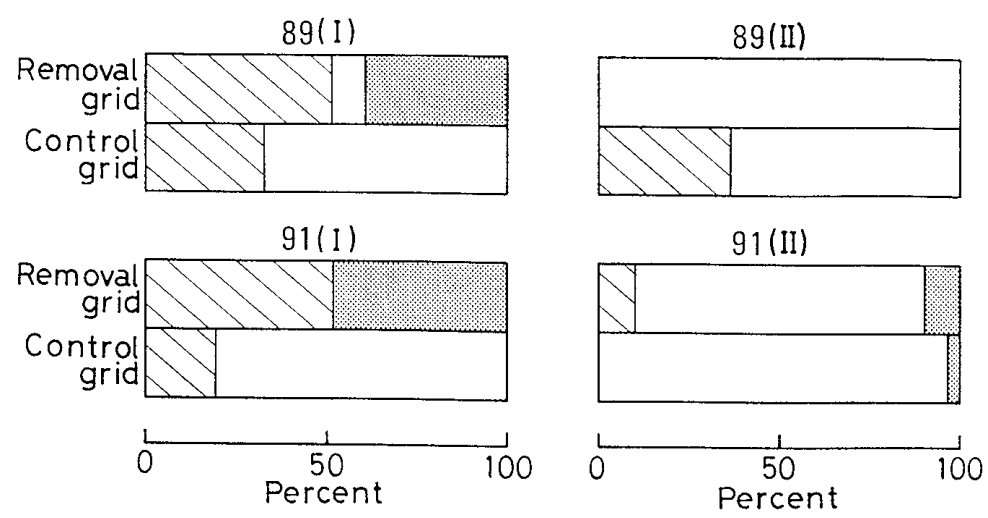

Fig. 1. Proportion of three categories of voles on grids after the removal. Hatched rectangles: newly trapped voles; open rectangles: marked voles in that grid; shaded rectangles: marked voles moving from the neighbor grid. The abbreviations, 89 (I), 89 (II), 91 (I) and 91 (II) designate periods I and II in 1989 and 1991.

immature with unopened vaginas or small testes. Although a small number of lactating females were observed in both 1989 and 1991, other individuals weighing $25 \mathrm{~g}$ or more were also immature or post-reproductive for both sexes in these years. A similar autumn composition of C. rufocanus was also obtained in another shelterbelt $50 \mathrm{~km}$ southwest of the present site (cf., ABE, 1976).

Effects of removal and source of voles

After the removal of 45 individuals in 1989 (80.4\% removal of the marked voles) and 104 individuals in $1991(100 \%)$, the marked voles of the adjacent control grid moved to the removal grid (Figs. 1 and 2). In period I of 1989, of twelve voles initially located within $30 \mathrm{~m}$ from the edge of the removal grid, eleven voles $(91.6 \%)$ moved toward that grid. On the other hand, of 27 voles marked at distances greater than $40 \mathrm{~m}$, twelve voles moved toward the removal grid, eleven voles moved away from it, and four voles did not move in either direction. Similar results were also found in 1991. In period II of 1989 and 1991, only two or less voles moved into the removal grid in spite of the density difference between the grids. The voles appeared to cease directional movements in that period.

Seven voles marked at sites more than $40 \mathrm{~m}$ from the removal grid invaded it in 1991, but none did so in 1989. Reinvasion into the removal grid was frequent in 1991, 
Table 2. Mean distance of vole movements $(\mathrm{m} \pm \mathrm{SD})$ by direction and period

\begin{tabular}{|c|c|c|c|c|c|c|}
\hline \multirow{3}{*}{ Period } & \multicolumn{6}{|c|}{ Direction of movements } \\
\hline & \multicolumn{3}{|c|}{ Toward left } & \multicolumn{3}{|c|}{ Toward right } \\
\hline & Males & Females & $P_{\mathrm{a}}$ & Males & Females & $P^{\mathrm{a}}$ \\
\hline $89(\mathrm{I})$ & $30.6 \pm 26.6(16)$ & $40.8 \pm 43.9(8)$ & ns & $9.4 \pm 4.5(8)$ & $9.0 \pm 6.6(5)$ & $\mathrm{ns}$ \\
\hline $89(\mathrm{II})$ & $7.6 \pm 3.3(7)$ & $35.6 \pm 47.2(3)$ & $\mathrm{ns}$ & $10.0 \pm 3.3(3)$ & $26.7 \pm 37.6(3)$ & $\mathrm{ns}$ \\
\hline $91(\mathrm{I})$ & $52.4 \pm 65.7(18)$ & $38.8 \pm 48.3(13)$ & ns & 103.3 & $6.4 \pm 2.4(7)$ & - \\
\hline $91(\mathrm{II})$ & $31.2 \pm 51.3(7)$ & $14.4 \pm 8.5(9)$ & $\mathrm{ns}$ & $21.5 \pm 33.2(11)$ & $13.6 \pm 16.5(7)$ & $\mathrm{ns}$ \\
\hline
\end{tabular}

a ManN-Whitney $U$-test to evaluate the equality of measurements on two sexes; ns: $p>0.05$. For individual voles, movement distances were measured along a "horizontal" axis. Numbers in parentheses are sample size.

when even voles located at more than $100 \mathrm{~m}$ away moved into the removal grid. The cause of such inter-year difference may be the result of the higher removal rate in 1991.

During period I, mean distance of movements toward (or to) the removal grid measured $30.6 \mathrm{~m}$ for males and $40.8 \mathrm{~m}$ for females in 1989, and $52.4 \mathrm{~m}$ for males and $38.8 \mathrm{~m}$ for females in 1991. These differences were not significant between the sexes (MANN-Whitney $U$-test: $U_{\mathrm{S}}=69$ in $1989 ; U_{\mathrm{S}}=130.5$ in 1991 ; Table 2 ). On the other hand, movements away from the removal grid were rather short during period I: $9.4 \mathrm{~m}$ for males and $9.0 \mathrm{~m}$ for females in 1989 , and $103.3 \mathrm{~m}$ for males and $6.4 \mathrm{~m}$ for females in 1991, with insignificant differences between the sexes (Table 2). In period II of 1989, mean distances of movements toward (or to) the removal grid were shorter than those of period I in both sexes, whereas opposite movements were longer (Table 2). The same results were also found in period II of 1991. Moreover, the differences in the distances were insignificant between the sexes (Table 2).

On the longest distance movement in period I, an immature male weighing $24 \mathrm{~g}$ moved $130 \mathrm{~m}$ in 1989, and an immature male $(22 \mathrm{~g}$ ) traveled $185 \mathrm{~m}$ in 1991 (voles with asterisk in Fig. 2). These were invaders of the removal grid. During period II, an immature female $(16 \mathrm{~g})$ moved $95 \mathrm{~m}$ in 1989, and a post-reproductive male $(27.5 \mathrm{~g})$ moved $146 \mathrm{~m}$ in 1991; these movements were directed toward (or to) the removal grid. For comparison with other studies, the mean distance of movements during period I, calculated only for the voles that invaded the removal area, was $58.2 \pm$ $38.3 \mathrm{~m}$ (mean $\pm \mathrm{SD} ; N=12)$ in 1989 and $94.2 \pm 58.2 \mathrm{~m}(N=13)$ in 1991.

\section{DISCUSSION}

A trap arrangement in a lattice of traps spaced $10 \mathrm{~m}$ apart may underestimate the population density because of incomplete exposure (TANAKA, 1980) and this was suggested by the appearance of many unmarked voles trapped during period II. On the other hand, a higher trap density possibly causes the voles' captures in the nearby traps, ceasing their potential movements. Hence our arrangement may be advantageous for monitoring post-removal movements.

Over $90 \%$ of the voles located within $30 \mathrm{~m}$ of the removal area moved toward (or to) a depopulated area in both 1989 and 1991 (Fig. 2). More than 50\% of the 

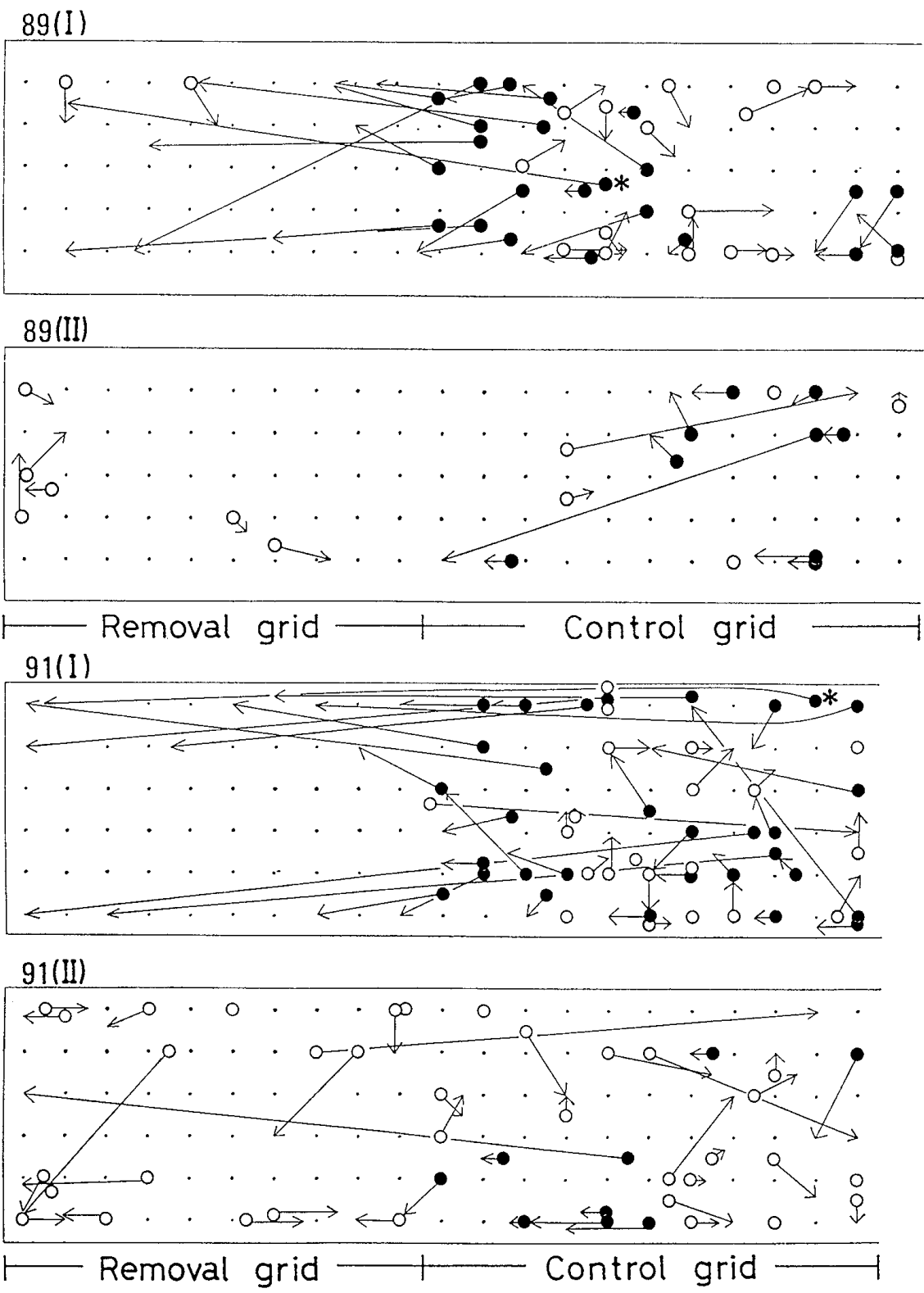

Fig. 2. Movements of voles after the removal. One circle represents one vole that was captured during the successive survey periods. Black circles: voles moving toward the left edge of the removal grid; open circles: other voles. Arrow indicates the direction of movement and its distance. Asterisk is attached to the longest distance movement recorded. Small dots include trapping sites, each of which were $10 \mathrm{~m}$ spaced apart. The outer line represents the boundary of the shelterbelt, and 89 (I), 89 (II), 91 (I) and 91 (II) are as in Fig. 1.

voles located more than $30 \mathrm{~m}$ away did not always move toward that area. Voles initially marked near a depopulated area apparently had a trend to invade the depopulated area. Similarly, Stickel (1946) and Higuchi (1966) reported that after successive daily removal, individuals taken in surrounding areas moved into the central depopulated area from all directions and from succeedingly greater distances.

In an autumn Clethrionomys rufocanus population with a density of 25 individuals/ha, 
most voles invading the central removal grid moved more than $50 \mathrm{~m}$ from the first point of capture (70-91 m means) (NAKATsu et al., 1989). These values were rather close to those of the present experiment in spite of the different density. On the other hand, SмYтн (1968) reported that most Clethrionomys glareolus voles moved less than $50 \mathrm{yd}(=45.7 \mathrm{~m})$ from June to October, and VAN VLECK (1968) recorded the average of $150 \mathrm{ft}(=45.7 \mathrm{~m})$ in a summer population of Microtus pennsylvanicus. Travel distances recorded in C. rufocanus populations are greater.

Contrary to the prediction that single-direction movements occur from the higherdensity area to the lower-density area in a homogenous habitat after depopulation, few voles invaded the removal grid in period II, when its density still differed from that of the adjacent control grid. Since dispersal is the lowest during the winter nonbreeding periods (KozAKIEwICZ, 1976; BEACHAM, 1980) and more dispersal occurs in increasing than in declining populations (Gaines and MoClenaGhan, 1980), singledirection movements may involve such seasonal and/or demographic factors. Actually, the non-breeding population in our study decreased in density in early winter. The relative importance of single factors in affecting movements needs examination in further research.

The buffer strip around the treatment perimeter has been promoted in application of rodenticide, to prevent vole invasions of the treated plantations. Accordingly, the baiting currently done in Hokkaido plantations includes a $30 \mathrm{~m}$-wide perimeter strip (cf., Nakata, 1988). However, using a much larger buffer strip has been advocated by other researchers (e.g., Higuchi, 1970). Our study has indicated that a $30 \mathrm{~m}$-wide strip (or zone) is in fact susceptible to a mass removal. The $30 \mathrm{~m}$-wide buffer strip currently used is therefore thought to be an effective measure to diminish reinvasion of the treated areas.

\section{ACKNOWLEDGMENTS}

We thank Y. Kitagawa, H. Hachiya, Y. Chiba and T. SAtoh for their assistance in the field.

\section{REFERENCES}

Abe, H. (1968) Growth and development in two forms of Clethrionomys. 1. External characters, body weight, sexual maturity and behaviour. Bull. Hokkaido For. Exp. Sta. 6: 69-89 (in Japanese with English summary).

ABE, H. (1976) Population structure and reproductive activity of Clethrionomys rufocanus bedfordiae (Thomas) in a wind shelter-belt of the Ishikari Plain, Hokkaido. J. Mamm. Soc. Jpn. 7: 17-30 (in Japanese with English abstract).

Beacham, T. D. (1980) Dispersal during population fluctuations of the vole, Microtus townsendii. J. Anim. Ecol. 49: 867-877.

Blair, W. F. (1940) A study of prairie deer-mouse populations in southern Michigan. Am. Midl. Nat. 24: 273-305 (cited from STICKel, 1946).

Gaines, M. S. and L. R. MaClenaghan, Jr. (1980) Dispersal in small mammals. Ann. Rev. Ecol. Syst. 11: 163-196.

Gaines, M. S. and M. L. Johnson (1987) Phenotypic and genotypic mechanisms for dispersal in Microtus populations and the role of dispersal in population regulation. In Mammalian Dispersal Patterns (B. D. Chepko-SAde and Z. T. HAlprn, eds.). Univ. Chicago Press, Chicago, pp. 162-179.

Hrguchr, S. (1966) The process of invasion of voles to controlled area and the provision of bait station. Proc. Hokkaido Branch, Jpn. For. Soc. 15: 129-131 (in Japanese). 
Higuchi, S., Y. FujImaki and T. TAkAyasu (1968) [Invasion of voles to man-made plantations.] HoppoRingyo 20: 310-313 (in Japanese).

Hrguchr, S. (1970) [Ecology of Small Rodents and Their Control.] Hoppo-Ringyo Kai, Sapporo, 86 pp. (in Japanese).

Higuchi, S. (1977) [Mammal pest.] In [Forest Protection in Hokkaido.] Hoppo-Ringyo Kai, Sapporo, pp. 134-155 (in Japanese).

Kozakiewicz, M. (1976) Migratory tendencies in population of bank voles and description of migrants. Acta Theriol. 21 : 321-338.

Kuwahata, T. (1976) Studies on population of the red-backed vole, Clethrionomys rufocanus bedfordiae (Thomas) (IV) Growth of the vole influenced by the ratio of combinations of the feeds and the nutritive materials during postnatal period in cage-reared stocks under the conditions. Bull. Gov. For. Exp. Sta. 284: 1-34 (in Japanese with English summary).

NaKata, K., K. SAKagughi, K. Kawabe and F. Hirota (1979) Reconfirmation of the effect of 1 percent zinc phosphide on the red-backed vole (Clethrionomys rufocanus bedfordiae). Bull. Hokkaido For. Exp. Sta. 16: 81-86 (in Japanese with English summary).

Nakata, K. (1988) [Zinc Phosphide Rodenticide-Its Qualities and Effects to the Environment.] Hokkaido Shinrin-hozen Kyokai, Sapporo, 23 pp. (in Japanese).

Nakatsu, A., T. Saitor, C. Hakamada and Y. Ozawa (1989) The management of the population of wild murid rodents in a small plantation area controlled by poisoned bait (a preliminary report) immigration of the grey red-backed vole, C. r. bedfordiae into the removal plot. Proc. Jpn. For. Soc. 100: 605-606 (in Japanese).

StENSETH, N. C. (1977) On the importance of spatio-temporal heterogeneity for the population dynamics of rodents: towards a theoretical foundation of rodent control. Oikos 29: 545-552.

Stiakel, L. F. (1946) The source of animals moving into a depopulated area. J. Mamm. 27: 301-307.

Sмyтн, M. (1968) The effects of the removal of individuals from a population of bank vole Clethrionomys glareolus. J. Anim. Ecol. 37: 167-183.

TANAKA, R. (1980) Controversial problems in advanced research on estimating population densities of small rodents. Res. Popul. Ecol. Suppl. 2, 67 pp.

VAN Vleck, D. B. (1968) Movements of Microtus pennsylvanicus in relation to depopulated area. J. Mamm. 49: 92-103. 